\title{
NASA's Earth Science Data Systems
}

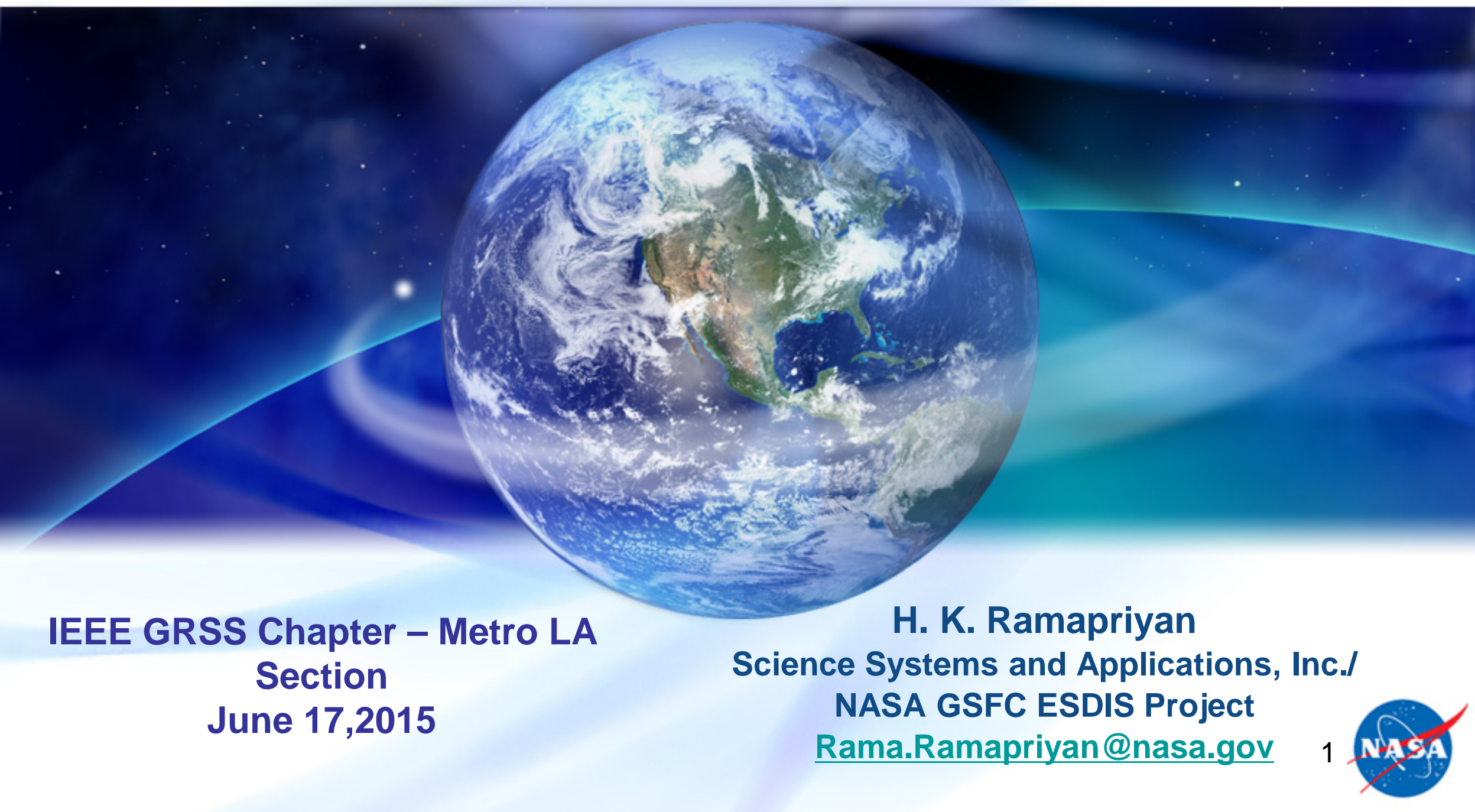




\section{Informatics}

- "Informatics (academic field), a broad academic field encompassing computing technologies and development in their diverse relations to the human and social worlds, including applications in science, social problems, and the arts" (Wikipedia - accessed Oct. 26, 2014)

- Science of information

- Practice of information processing, and engineering of information systems.

- Studies structure, algorithms, behavior, and interactions of natural and artificial systems which store, process, access, and communicate information.

- Considers interaction between humans and information systems alongside the construction of computer interfaces.

- Develops its own conceptual and theoretical foundations and utilizes foundations developed in other fields.

- Informatics has great breadth and encompasses many individual specializations including the more particular discipline of computing science 


\section{Earth Science Informatics}

- "Earth science informatics, as a specialized branch of informatics science, creates and processes information about the Earth system, to allow conceptualization, design, modeling, and implementation methodologies for the management, processing, and representation of the information and knowledge about the Earth." - Hassan A. Babaie (Editorial - Earth Sci Inform (2008) 1:1-2; DOI 10.1007/s12145-0080009-0)

- There are many definitions for informatics in general, and informatics in various Earth science domains. Rahul Ramachandran's blog http://www.rramachandran.com/content/science-informatics---whatname does a nice job of summarizing them. In his conclusion he quotes Tolliver:

- "It is a focus on a specific science domain in which information and computational sciences (including information science, library science, computer science, cognitive science, organizational science, etc.) are utilized to support research, education, and application". 


\section{GRSS Technical Committees}

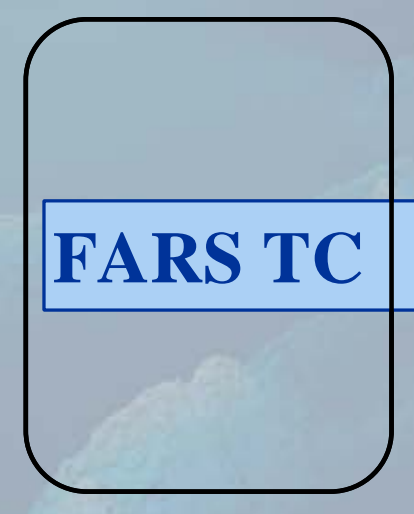

Regulations
Sensors
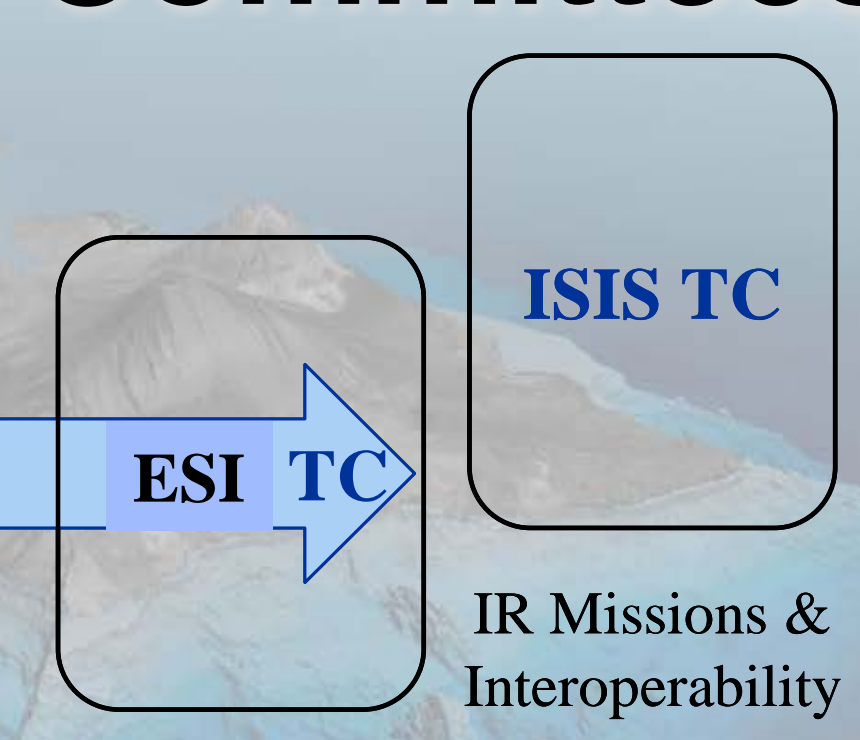

Analysis
Data Delivery

- FARS TC: Frequency Allocations in Remote Sensing - Regulatory Environment

- IFT TC: Instrumentation and Future Technologies - Development of Future Sensors \& Instruments

- IADF TC: Image Analysis and Data Fusion - Analysis Techniques for Complementary Datasets

- ESI TC: Earth Science Informatics - Standards, Data Access and Usability

-ISIS TC: Int'I Spaceborne Imaging Spectroscopy - International Satellite Mission Planning 


\section{Earth Science Informatics Technical Committee (ESI TC)}

- Mission

- "...to advance the application of informatics to the geosciences and remote sensing, to provide a venue for ESI professionals to exchange information and knowledge, and to give technology advice to major national and international ESI initiatives."

- Evolved from the former Data Archiving and Distribution (DAD) TC to be commensurate with member interests

- Leaders:

- Chair: Rahul Ramachandran (NASA Marshall Space Flight Center / Global Hydrology Resource Center, USA)

- Co-Chair: Peng Yue (Yuhan University, China)

- Standards Group: Siri Jodha Singh Khalsa (National Snow and Ice Data Center, University of Colorado, USA) 


\section{Earth Science Informatics - Scope}

- The scope of the original

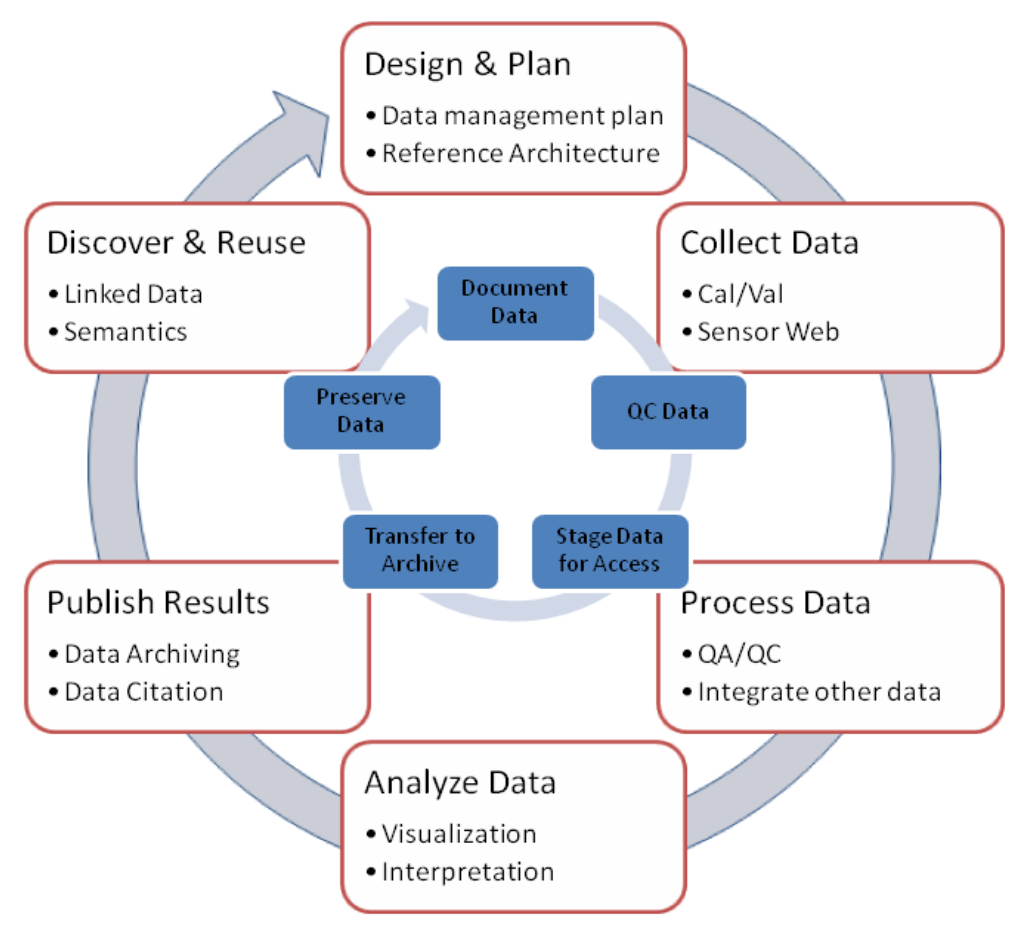
DAD TC was essentially limited to to the data lifecycle

- Knowledge generation lifecycle

- Depicts the sequence of processes involved in knowledge generation

- Useful in identifying where data and information can be enhanced or even lost

- Evolving - Data, Technology, Policy, End User

- Standards play important roles at each stage 


\section{ESI TC - Topics of Interest}

- Data and information policies, stewardship, preservation, provenance and quality

- Knowledge representation (ontologies, vocabularies, semantic web)

- Cyberinfrastructures

- Data discovery and access

- Tools supporting spatial and temporal analyses

- Emerging information technologies (Big Data) 


\section{Acknowledgement}

- This presentation is the result of my long association with the NASA Earth Science Data and Information System Project

- It has evolved over the years with inputs from several members of the Project and has been used in various forms in many presentations

- My present work with the ESDIS Project is supported under contract number NNG15HQ01C with NASA Goddard Space Flight Center 


\section{Topics}

- NASA's Earth Science Data Systems

- Core and Community Capabilities

- Earth Observing System Data and Information System (EOSDIS)

- Scope and Context

- System of systems

- EOSDIS Evolution - Community inputs

- IEEE GRSS Earth Science Informatics Technical Committee and EOSDIS

- Recent Developments

- Conclusion 


\section{NASA's Earth Science Data Systems}

- "Advance understanding of Earth and develop technologies to improve the quality of life on our home planet." -- 2014 NASA Strategic Plan

- NASA's Earth Science Data Systems directly support this strategic goal by providing endto-end capabilities to deliver data and information products to users

- NASA's Earth Science Data and Information Policy promotes usage of data by the community

- No period of exclusive access - Data are available after initial checkout

- Data available at no cost to all users on a non-discriminatory basis except where agreed upon with international partners 


\section{Core and Community Capabilities}

\section{- Core Capabilities}

$>$ Basic operational capabilities to process, archive, manage and distribute data from NASA missions

* Earth Observing System Data and Information System (EOSDIS)

* Precipitation Processing System - NASA GSFC

- Laboratory for Atmospheric and Space Physics (LASP) Interactive Solar Irradiance Data Center - University of Colorado

* CloudSat Data Processing Center - Colorado State University

- Community Capabilities

$>$ Peer-review-selected projects

$>$ New data products - Making Earth System Data Records for Use in Research Environments (MEaSUREs)

$>$ Research in Earth Science Informatics to feed into the evolution of the core components

* Applied Information Systems Technology (AIST)

* Advancing Collaborative Connections for Earth System Science (ACCESS) 


\section{EOSDIS}

- Major core capability in NASA's Earth Science Data Systems Program.

- Provides end-to-end capabilities for managing NASA's Earth science data.

$>$ Science Operations

* Science data processing

* Data management

* Interoperable distributed data archives

* On-line data access services

* Earth science discipline-oriented user services

$>$ Network Data Transport to distributed system elements 


\section{Extensive Data Collection}

- >8200 data types (collections)

- Land

» Cover \& Usage

»Surface temperature

»Soil moisture

» Surface topography

- Atmosphere

»Winds \& Precipitation

»Aerosols \& Clouds

» Temperature \& Humidity

»Solar radiation

- Ocean

»Surface temperature

» Surface wind fields \& Heat flux

» Surface topography

»Ocean color

- Cryosphere

» Sea/Land Ice \& Snow Cover

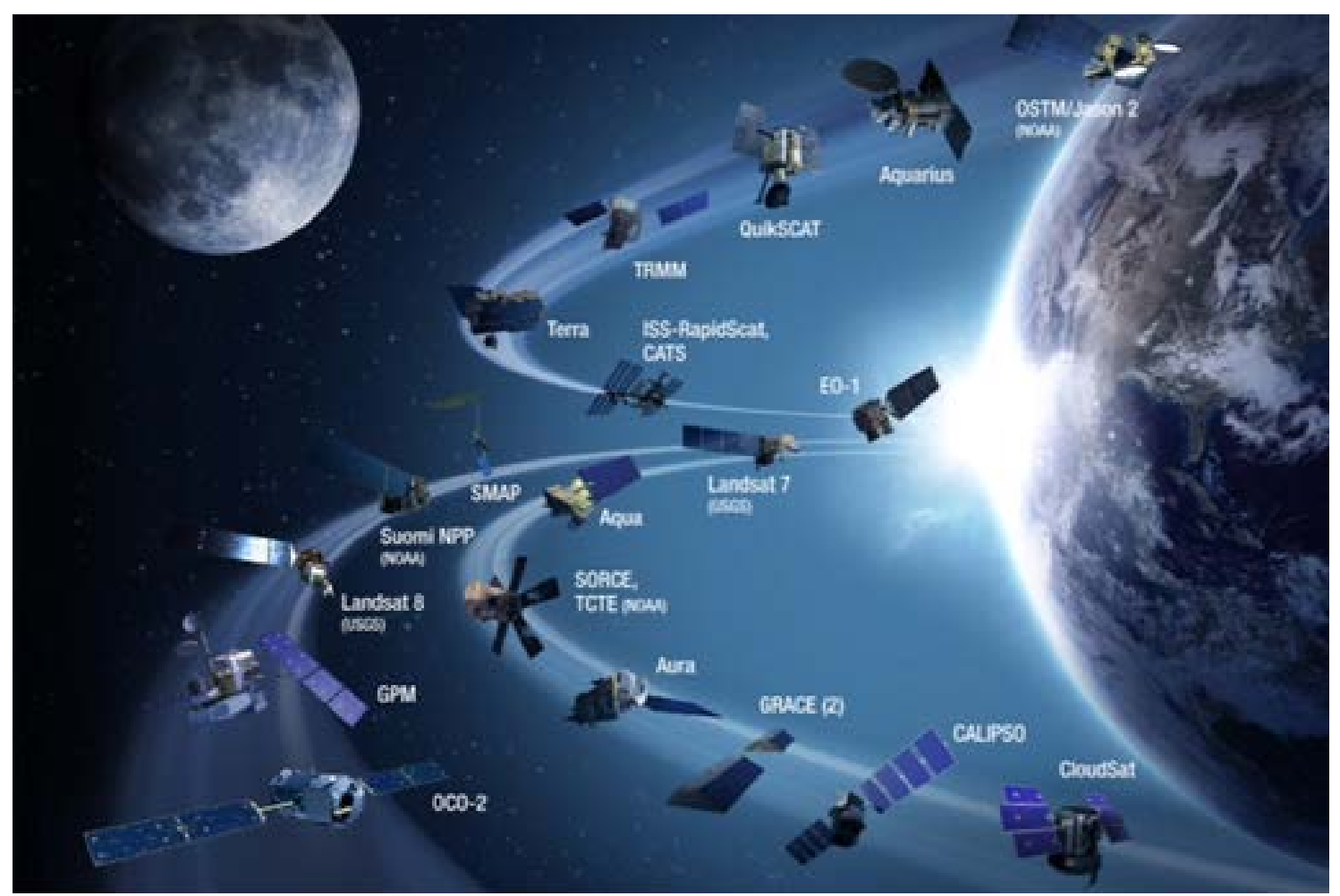

- Human Dimensions

» Population \& Land Use

» Human \& Environmental Health

» Ecosystems 


\section{Earth Science Data Operations}

\section{Mission Operations}

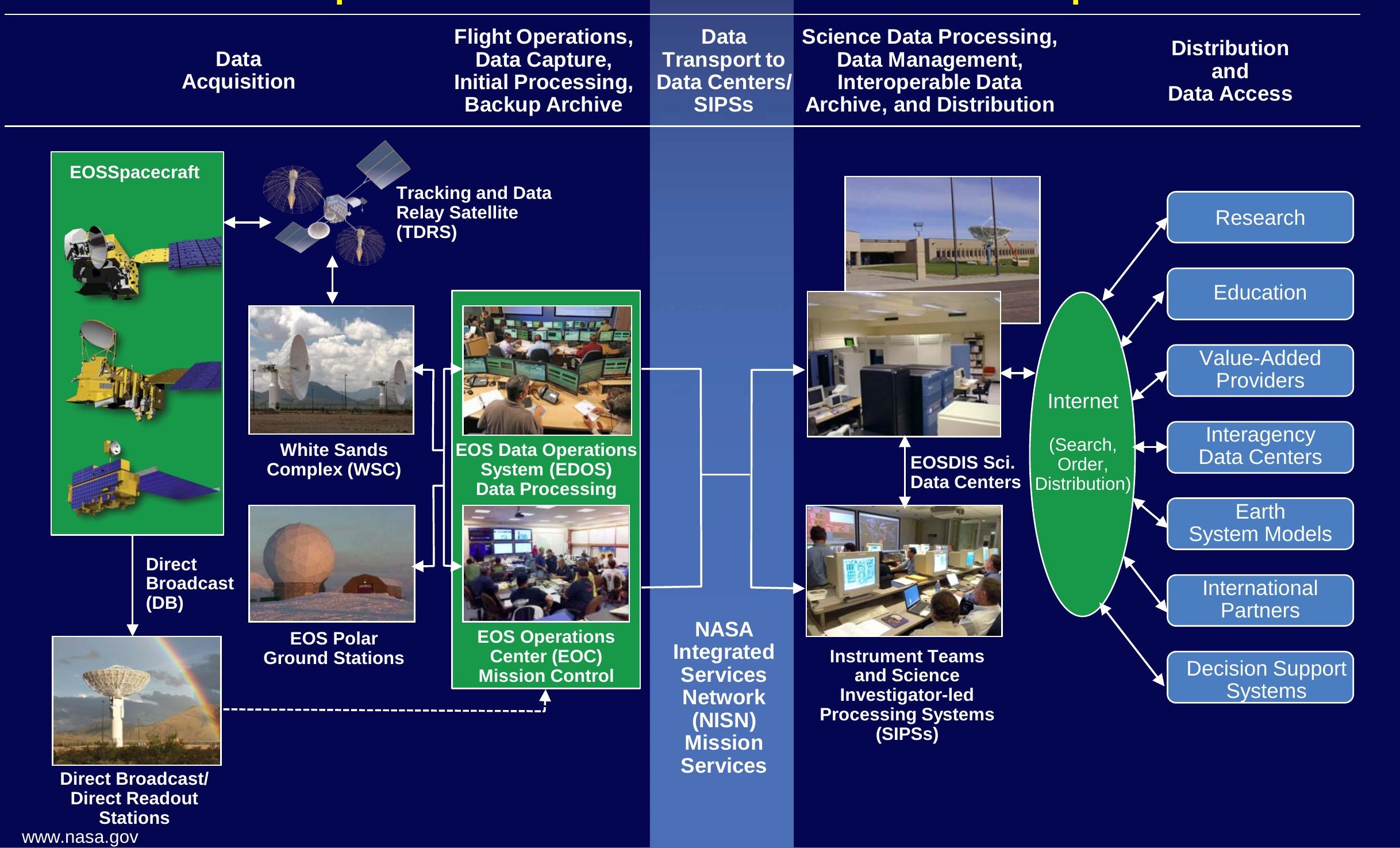




\section{Organizational Architecture and Interfaces}

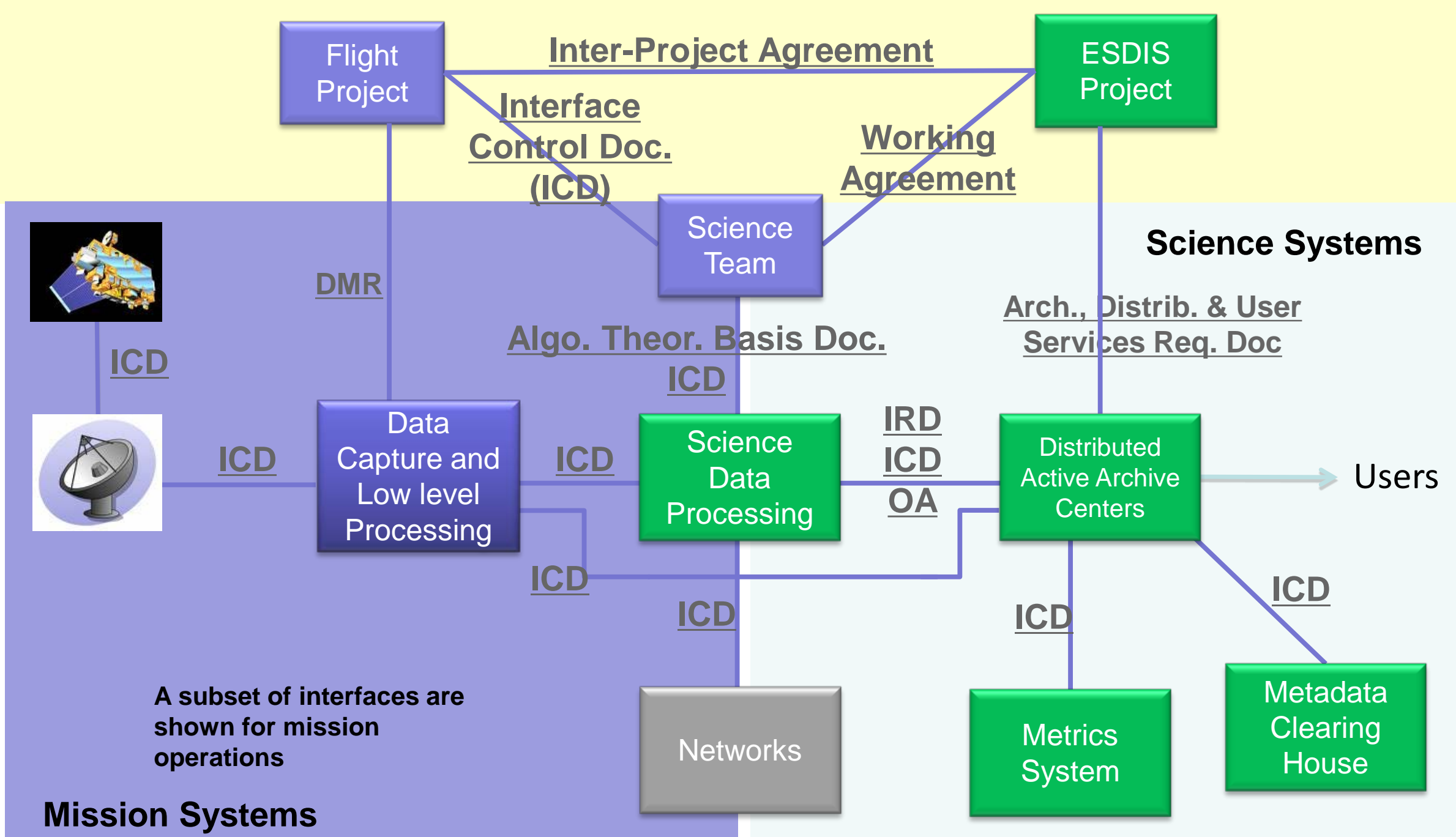




\section{Key Life Cycle Phases*}

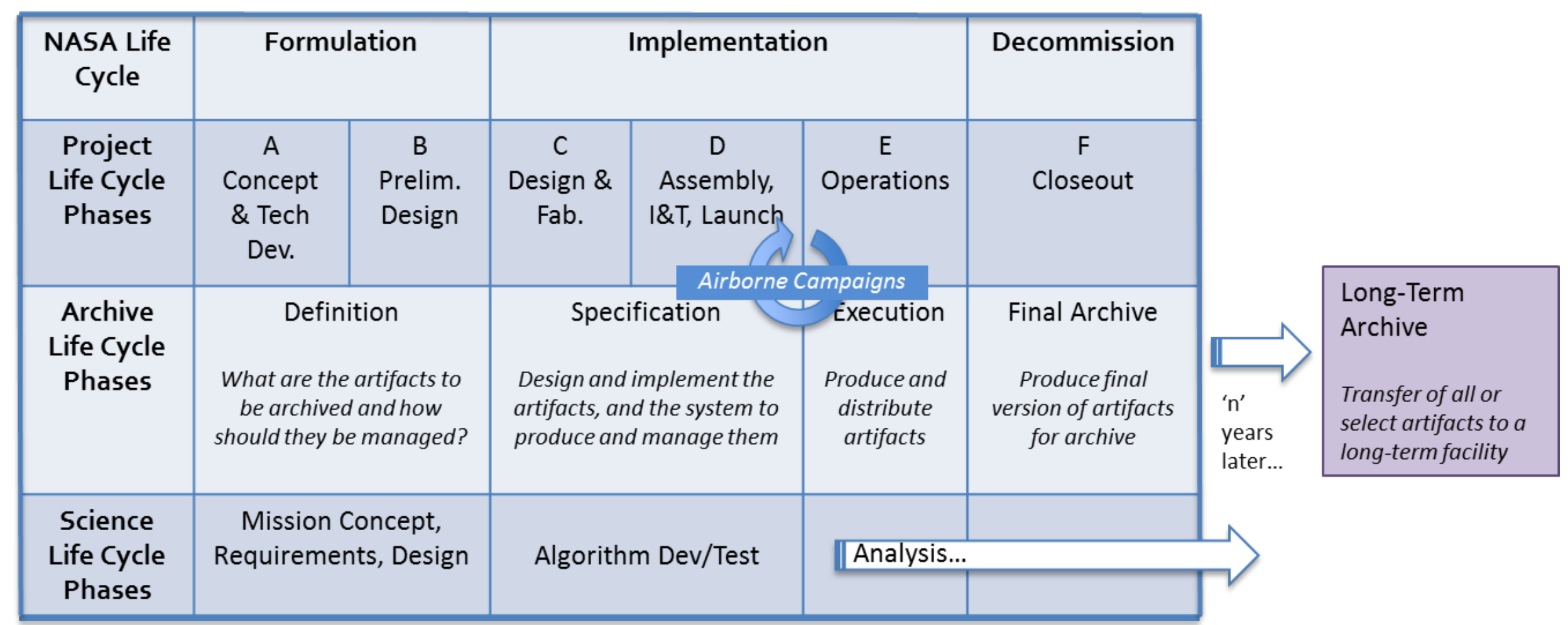

*Credit - Data Preservation Practices Working Group - 2014-2015 (NASA Earth Science Data System Working Groups) 


\section{EOSDIS - A System of Systems}

- Instrument and science expertise needed to process data

- Most EOS standard products are generated at Science Investigator-led Processing Systems (SIPSs) under supervision of PIs

- Earth Science discipline knowledge needed to ensure data stewardship

- Processed data are archived and distributed by discipline-specialized EOSDIS Science Data Centers (Distributed Active Archive Centers DAACs)

- Expertise in system interoperability needed to provide crosssystem (interdisciplinary) data access

- EOS Clearing House (ECHO) middleware and associated clients provide search and access to data across all EOSDIS Science Data Centers

- EOSDIS data collections are diverse:

- Primary sources are instruments on-board NASA spacecraft

- Ancillary, airborne, in-situ and socio-economic data

- Data from international partners

- Comprehensive approach to multi-discipline science

- Feed growing need by models (e.g., climate models) 


\section{EOSDIS Facilities}

ASF DAAC

SAR Products

Sea Ice, Polar

Processes

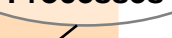

\section{Data centers, collocated with centers of science discipline expertise, archive and distribute standard data products produced by Science Investigator-led Processing Systems (SIPSs)}

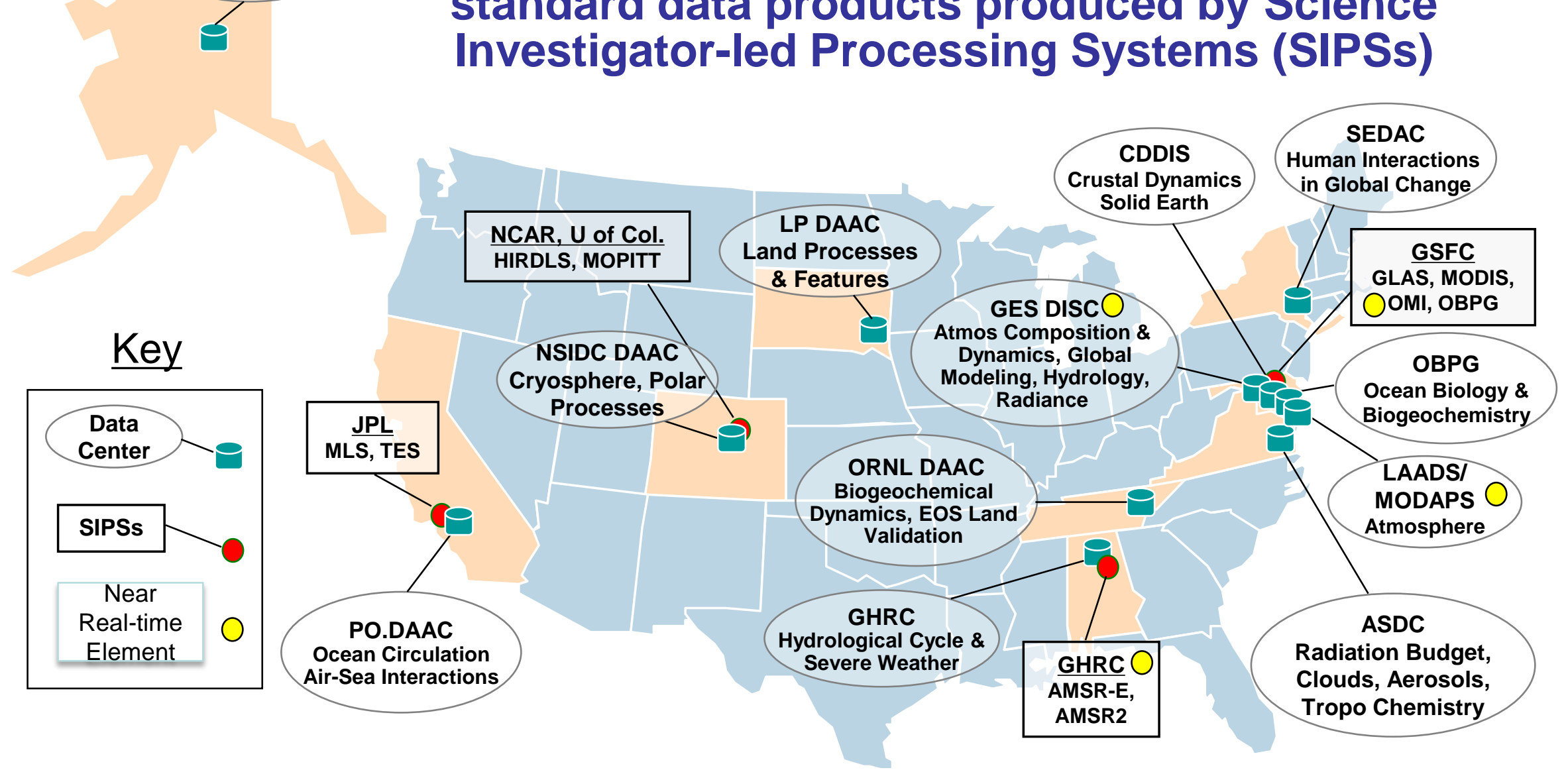




\section{EOSDIS Key Metrics}

EOSDIS FY2014 Metrics

(Oct. 1, 2013 to Sept. 30, 2014)

\begin{tabular}{|l|c|}
\hline Unique Data Sets & 8,292 \\
\hline $\begin{array}{l}\text { Distinct Users of EOSDIS Data and } \\
\text { Services }\end{array}$ & $2.0 \mathrm{M}$ \\
\hline Web Site Visits & $2.3 \mathrm{M}$ \\
\hline Average Archive Growth & $6.4 \mathrm{~TB} / \mathrm{day}$ \\
\hline Total Archive Volume & $9.1 \mathrm{~PB}$ \\
\hline End User Distribution Products & $1,028 \mathrm{M}$ \\
\hline $\begin{array}{l}\text { End User Average Distribution } \\
\text { Volume }\end{array}$ & $27.9 \mathrm{~TB} /$ day \\
\hline
\end{tabular}

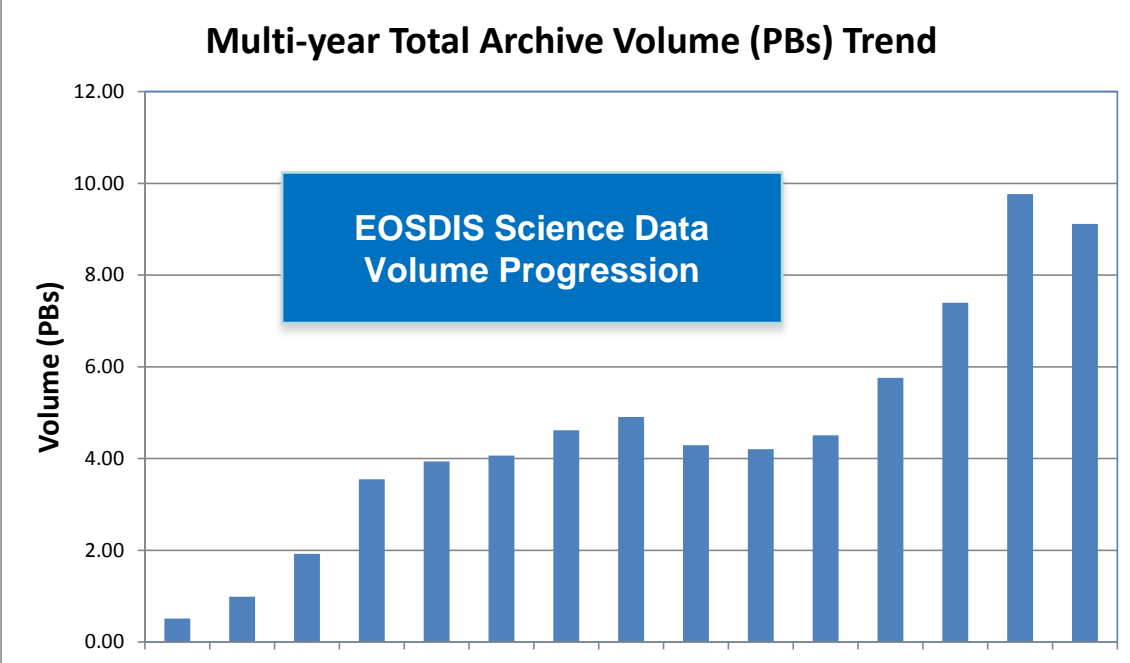

FY00 FY01 FY02 FY03 FY04 FY05 FY06 FY07 FY08 FY09 FY10 FY11 FY12 FY13 FY14
Distribution by Discipline

Product Counts (M)

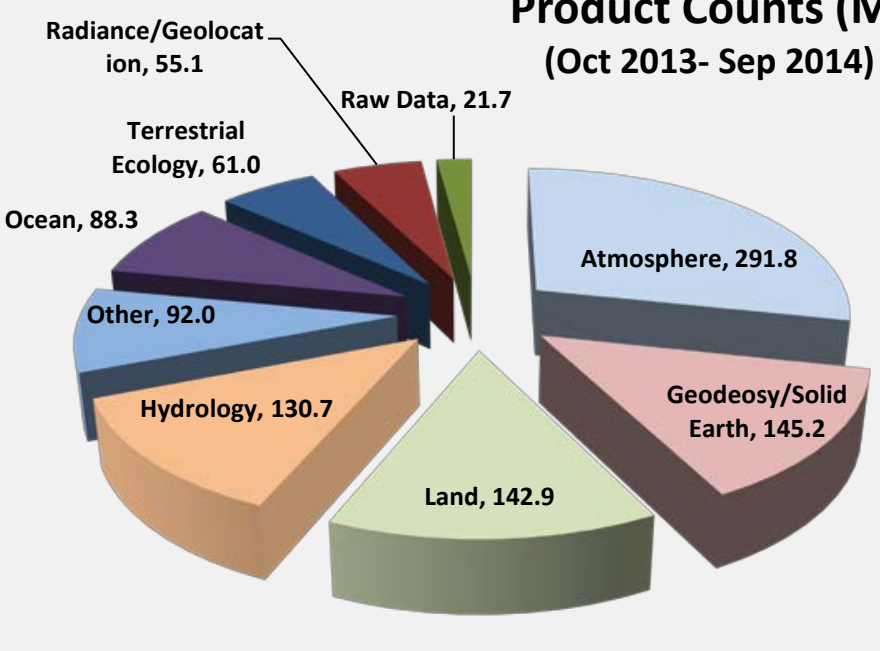

Multi-Year Product Distribution Trend

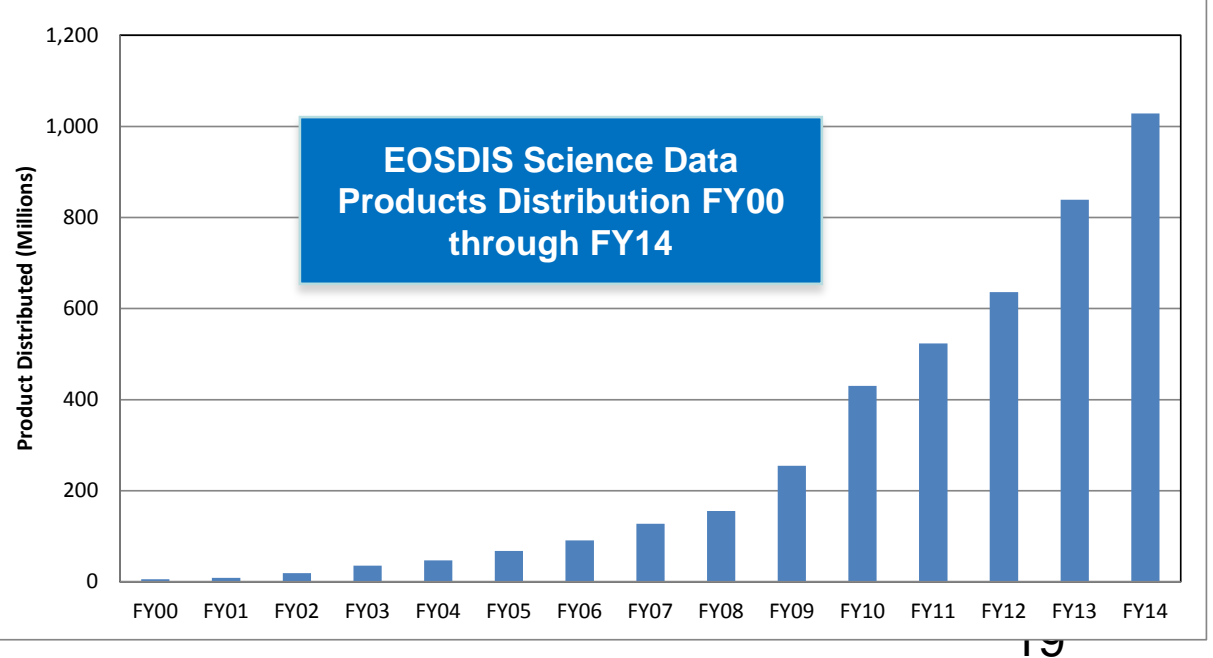




\section{EOSDIS Evolution - Community Inputs}

- EOSDIS Advisory Panel - aka Data Panel (early to mid-1990's)

- adhere to a flexible, distributed, portable, evolutionary design;

- distribute data products by appropriate high-bandwidth communication or other media;

- operate prototypes in a changing experimental environment

$\rightarrow$ Distributed architecture with DAACs

$\rightarrow$ Version 0 working prototype

- NRC Review (1995)

- "Responsibility for product generation and publication and for user services should be transferred to a federation of partners selected through a competitive process open to all"

$\rightarrow$ Working Prototype Earth Science Information Partners (ESIP) Federation 


\section{EOSDIS Evolution - Community Inputs}

- EOSDIS Review Group (1997)

- Recommended "an adaptive approach which will be less centralized, giving more responsibility to the PIs"

$\rightarrow$ Science Investigator-led Processing System (SIPSs)

- New Data and Information Systems and Services (NewDISS) Strategy Team (1998 - 2002)

- Six recommendations

- Clearly define components

- Employ Infrastructure providing NASA-private sector liaisons

- Employ competitive processes to select components

- Empower science investigators for data system development, processing archiving and distribution

- Apply lessons learned from WP-ESIP Federation

- Charter transition team

$\rightarrow$ Core and Community Data Systems (Core: EOSDIS with DAACs;

Community: REASoN projects $\rightarrow$ ACCESS \& MEaSUREs)

$\rightarrow$ ESIP Federation

$\rightarrow$ Strategic Evolution of Earth Science Enterprise (ESE) Data Systems

(SEEDS) Study $\rightarrow$ Earth Science Data System Working Groups (ESDSWG, 2004) 


\section{EOSDIS Evolution - Community Inputs}

- Evolution of EOSDIS Elements Study Team/ Technical Team (2005)

- Developed "EOSDIS 2015 Vision"

$\rightarrow$ First step implementation during 2006-2008 - reallocated functions, simplified system, increased automation, improved services, reduced operations costs

$\rightarrow$ Vision tenets continue to be used as a checklist to assess progress of on-going improvements

- DAAC User Working Groups (on-going)

- American Customer Satisfaction Index Surveys (annual) 


\section{EOSDIS Evolution - Community Inputs}

- Earth Science Data System Working Groups (ongoing)

- focus on exploration and development of recommendations derived from pertinent community insights

- organized around key technology and information system issues

- Members from ACCESS, MEaSUREs, DAACs, ESDIS

- 2014-2015 Working Groups

Airborne Data

ASCII for Science Data

Cloud Computing

Data-Intensive Architecture

$\square$ Data Preservation Practices

Data Quality

Data Recipes

Dataset Interoperability $\square$ Digital Object Identifiers

- Geospatial

Innovations Lab

Open Source

Provenance for Earth Science (PROV-ES)

Technology Infusion

vision 2020

口 Visualization 


\section{ESDSWG $\leftrightarrow \rightarrow$ IEEE GRSS ESI TC}

\begin{tabular}{|c|c|c|}
\hline & ESDSWG & Earth Science Informatics Technical Committee \\
\hline Processing & $\begin{array}{l}\text { - } \text { Cloud Computing } \\
\text { - Data-Intensive Architectures }\end{array}$ & $\begin{array}{l}\text { - Cloud Computing } \\
\text { - Spatial/Temporal analysis Tools } \\
\text { - Earth system modeling tools }\end{array}$ \\
\hline \begin{tabular}{|l|} 
Archiving/ \\
Stewardship
\end{tabular} & $\begin{array}{l}\text { - Data Preservation Practices } \\
\text { - Data Quality } \\
\text { - Digital Object Identifiers } \\
\text { - PROV-ES }\end{array}$ & $\begin{array}{l}\text { - Preservation } \\
\text { - Quality } \\
\text { - Data stewardship } \\
\text { - Provenance }\end{array}$ \\
\hline Access & $\begin{array}{l}\text { - Recipes } \\
\text { - Dataset Interoperability } \\
\text { - Visualization } \\
\text { - Geospatial }\end{array}$ & $\begin{array}{l}\text { - Knowledge representation and information models } \\
\text { - } \text { Cyberinfrastructures } \\
\text { - Interoperability and standardization } \\
\text { - Data discovery and access } \\
\text { - Web-based services and analysis } \\
\text { - Geospatial information, knowledge, and decision support } \\
\text { systems }\end{array}$ \\
\hline \begin{tabular}{|l} 
Evolutionl \\
Technology
\end{tabular} & $\begin{array}{l}\text { - Innovations Lab } \\
\text { - Open Source } \\
\text { - Technology Infusion } \\
\text { - Vision } 2020\end{array}$ & $\begin{array}{l}\text { - Emerging information technologies and their applications in } \\
\text { the geosciences } \\
\text { - Sensor web and applications } \\
\text { - spatial and process ontologies, vocabularies } \\
\text { - semantic web }\end{array}$ \\
\hline Other & $\begin{array}{l}\text { - Airborne Data } \\
\text { - ASCII for Science Data }\end{array}$ & - Data and information policies \\
\hline
\end{tabular}




\section{Vision 2020}

\begin{tabular}{|c|c|c|c|}
\hline \multicolumn{2}{|r|}{ Discovery and Access } & \multicolumn{2}{|r|}{ Usage } \\
\hline$\square$ & $\begin{array}{l}\text { Machine Level Discovery and Access for all } \\
\text { data. }\end{array}$ & $\square$ & $\begin{array}{l}\text { Intelligent Tool Catalogs suggest tools to work } \\
\text { with the data. }\end{array}$ \\
\hline \multirow[t]{2}{*}{$\begin{array}{l}\square \\
\square\end{array}$} & $\begin{array}{l}\text { Seamless Cross-agency Discovery. } \\
\text { Dataset Selection Guidance based on fitness }\end{array}$ & $\square$ & $\begin{array}{l}\text { Publications are linked to data and tools that } \\
\text { allow interactions with the data. }\end{array}$ \\
\hline & $\begin{array}{l}\text { for purpose. } \\
\text { Metadata Naming Conventions for }\end{array}$ & $\square$ & $\begin{array}{l}\text { Automatic Mobile Data and Processing to } \\
\text { achieve optimal performance. }\end{array}$ \\
\hline \multirow{2}{*}{$\square$} & Variables, Platforms, Instruments, & \multirow{2}{*}{$\begin{array}{l}\square \\
\square\end{array}$} & Quantitative Quality for all data. \\
\hline & $\begin{array}{l}\text { Resolution... } \\
\text { Virtual Collections oriented around science }\end{array}$ & & $\begin{array}{l}\text { Reproducibility of research results with high } \\
\text { precision. }\end{array}$ \\
\hline$\square$ & problems. & \multirow[t]{2}{*}{$\square$} & \multirow{2}{*}{$\begin{array}{l}\text { Documentation is Concise, Comprehensive and } \\
\text { Consistent for all data variables. }\end{array}$} \\
\hline & Integration & & \\
\hline \multirow{3}{*}{$\begin{array}{l}\square \\
\square \\
\square \\
\square\end{array}$} & $\begin{array}{l}\text { NASA data can be combined with data from } \\
\text { other agencies and nations. } \\
\text { Combining Tools and Services within the }\end{array}$ & $\square$ & $\begin{array}{l}\text { Capacity Building mechanisms for people with } \\
\text { limited literacy in science, technology, and/or } \\
\text { English. }\end{array}$ \\
\hline & $\begin{array}{l}\text { community is easy. } \\
\text { Enable sharing of any scientific resource. }\end{array}$ & $\square$ & $\begin{array}{l}\text { Data Analysis at Scale over any arbitrarily } \\
\text { defined area. }\end{array}$ \\
\hline & & $\square$ & $\begin{array}{l}\text { Dataset Upgrading for high-value datasets to } \\
\text { fully support rich capabilities. }\end{array}$ \\
\hline
\end{tabular}




\section{Recent and On-Going Developments (1 of 2)}

- Land and Atmosphere Near real-time Capability for EOS (LANCE)

- Coherent Web Interface: http://earthdata.nasa.gov is operational

- Provides a unified view of NASA Earth science data system resources

- Consolidates 14 web sites, and provides links to various ways to access data and to related external sites

- User Registration System - uniform approach to registration across EOSDIS components

- Global Imagery Browse Services (GIBS)

- Standards-based, full resolution, interactive browse capability

- Accessible from http:/learthdata.nasa.gov wiki 


\section{Recent and On-Going Developments (2 of 2)}

- Metadata Architecture Study

- Initial Study made recommendations on adopting a common approach to metadata to improve user experience and reduce efforts by data providers

- Phased approach to implementing recommendations

- Unified Metadata Model and Common Metadata Repository

- Big Earth Data Initiative (BEDI)

- Preservation Content Specification

- Digital Object Identifiers

- ESDIS Project is a registration authority (prefix 10.5067)

- DOI assignments to datasets in progress 
- Building on existing EOSDIS elements provides data from MODIS, OMI, AIRS, MLS, and AMSR instruments in near real-time $(<3$ hours from observation)

- Utilizes software for Standard Science Products, but relaxes requirements for ancillary data inputs

- High operational availability

- Applications of LANCE data include:

- Numerical weather \& climate prediction/forecasting

- Monitoring of Natural Hazards

- Disaster Relief

- Agriculture

- Air quality

- Homeland Security

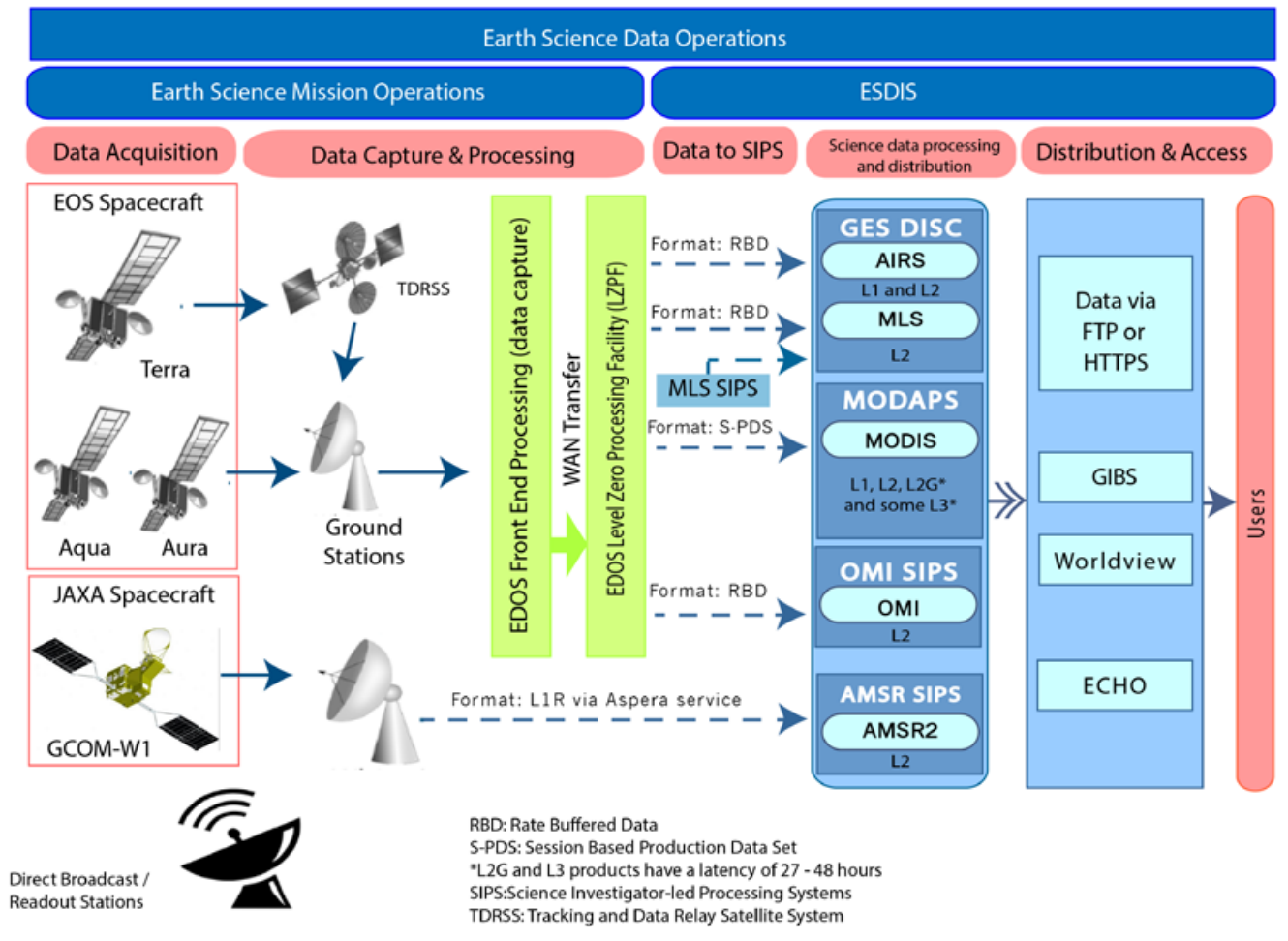




\section{LANCE Latencies}

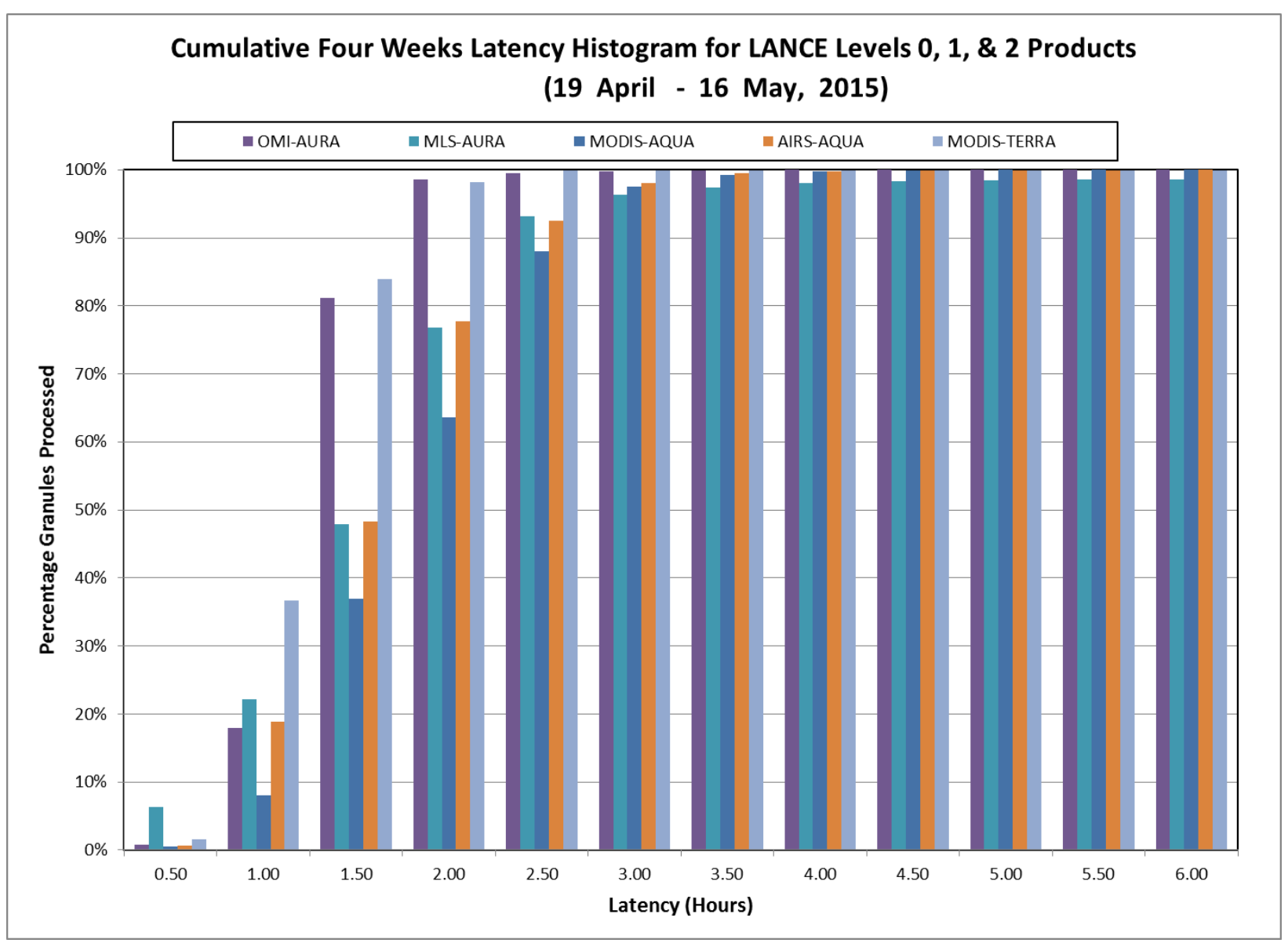

Over the four weeks indicated above, $>97 \%$ of near real-time data requests were satisfied within 3 hours. 


\section{EOSDIS Evolution: Earthdata Website}

What is the Earthdata Website?

- Earthdata was created as a sustainable, evolvable, and reliable Website that represents our community's needs for NASA Earth science data and information.

- It was designed to support collaboration within and between organizations, and for development and integration of new applications.

- It addresses the need for a coherent and comprehensive Web presence of the Earth Science Data Systems Program.

- See Earthdata at https://earthdata.nasa.gov/.

- Benefits of the Earthdata Website:

- Better represents EOSDIS programmatic investments and capabilities.

- Presents data centers more clearly as elements within a larger system of systems.

- Facilitates multidisciplinary research and data integration.

- More quickly responds to emerging technologies

- Provides a platform for demonstration of interoperability throughout all of our systems.

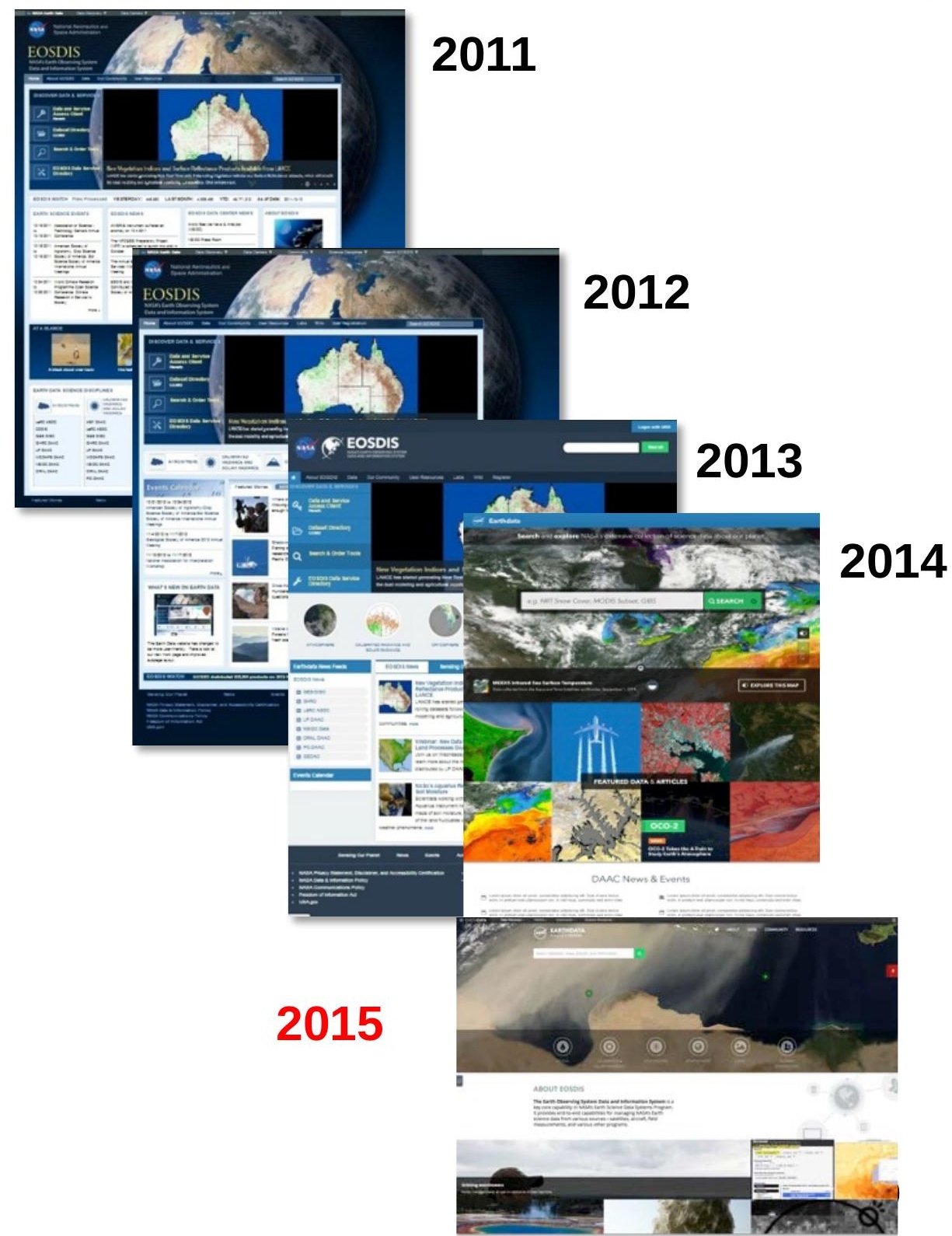




\section{EOSDIS Evolution: Worldview and Global Browse Imagery Services}

\section{GIBS / Worldview Goal:}

To transform how users interact with and discover NASA Earth data; make it visual

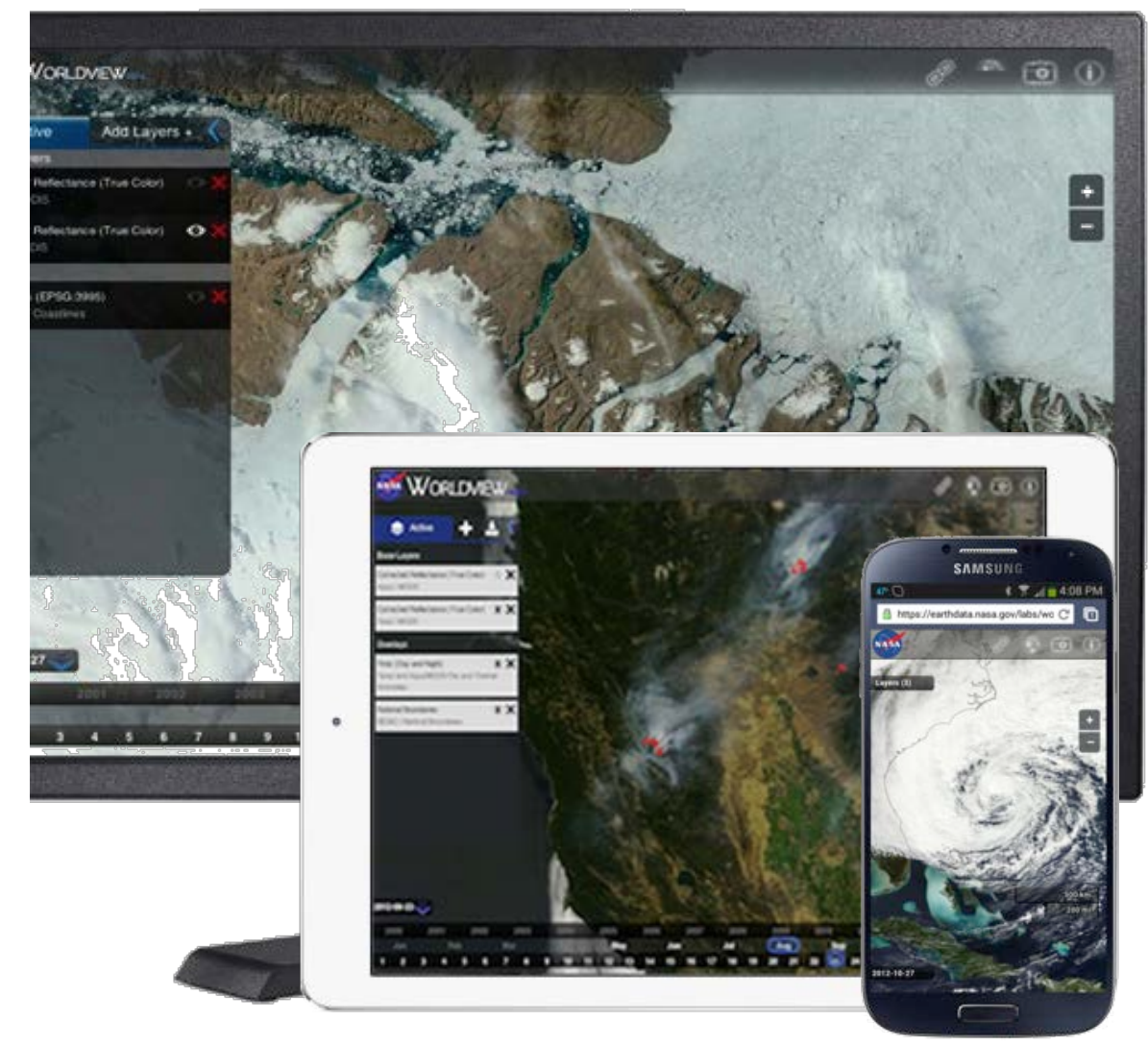

Approach:

- The Global Imagery Browse Services (GIBS) provide open access to full resolution imagery derived from NASA products to any mapping client and script

https://earthdata.nasa.gov/gibs

- Worldview is an open source, browserbased client to interactively explore GIBS (and SEDAC) imagery and download the underlying data https://worldview.earthdata.nasa.gov 


\section{Global Image Browse Service (GIBS)}

- Goal: "Parameter Visualizations" for all EOSDIS Imagery

- Standardized access via OGC WMTS / TWMS / WMS / KML

- Source code for the GIBS OnEarth server and sample code available at the GIBS GitHub site

- Repository of pre-prepared, hierarchically stored imagery to maximize performance for "full-resolution" browse

- Clients can be built to use and display images in GIBS - WorldView is an example 


\section{Worldview: Reference Client for GIBS}

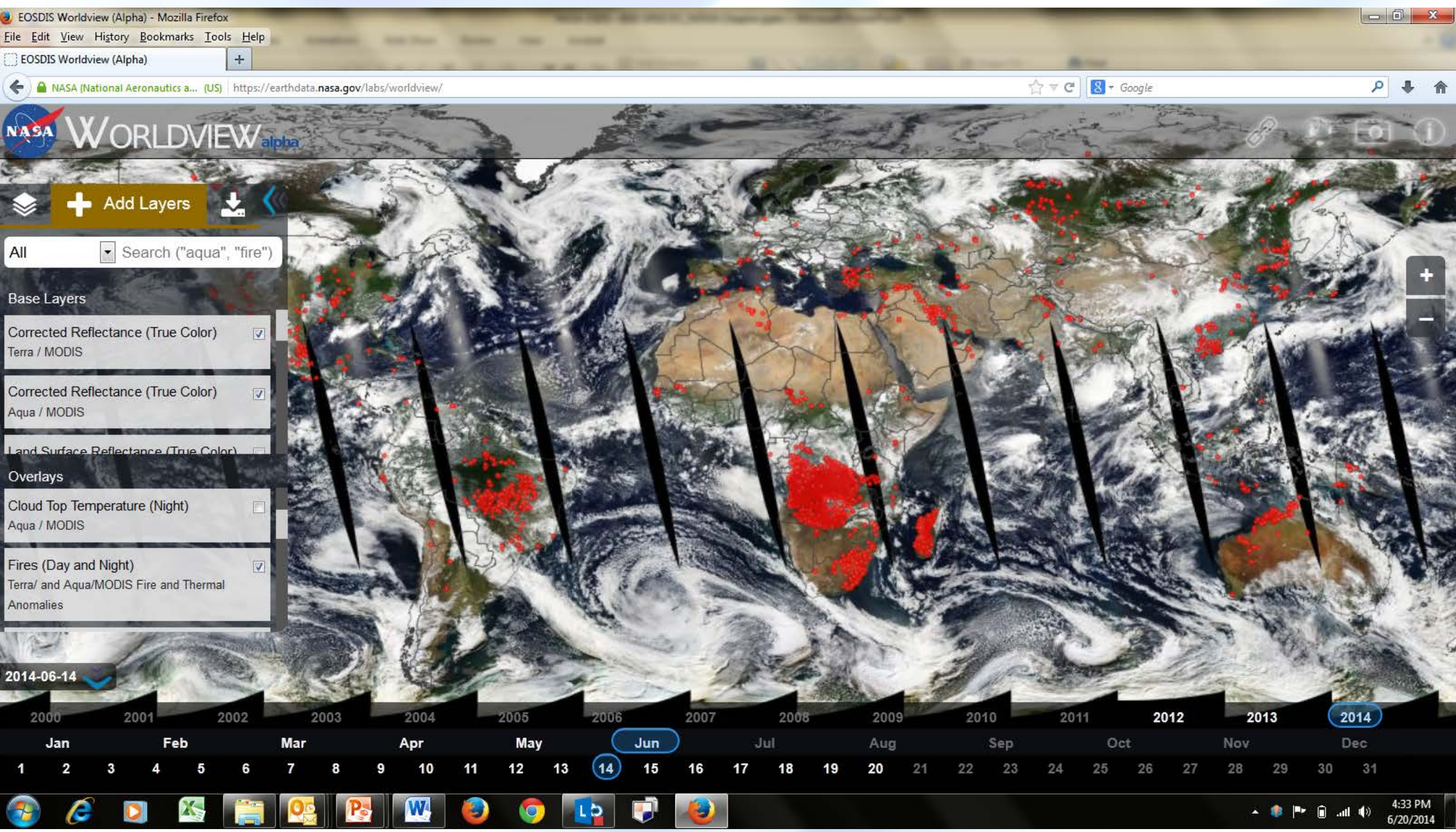




\section{Common Metadata Repository (CMR)}

- Goals

- Designed to improve the discovery and access of NASA data, CMR will provide a single source of unified, high-quality, and reliable Earth Science metadata while merging the inventories of ECHO (EOS Clearing House) and GCMD (Global Change Master Directory) / IDN (International Directory Network). CMR will be the authoritative management system for all metadata of EOSDIS data holdings.

- CMR also provides a metadata model that documents vital elements that may be represented across various metadata formats and standards and unify them through core fields useful for data discovery and service invocations.

\section{- Current Status}

- By the end of CY 2015, CMR will have released the minimal set of functionality that addresses the major goals laid out in a CMR Operations Concept including, sub-second search response, unification of ECHO and GCMD/IDN metadata, enhanced metadata management capabilities, and a unified (and expandable) metadata model representing collections, granules, and services.

\section{- Next Steps}

- In 2016, CMR will begin to implement enhancements to quality assessment and assurance, search relevancy ranking, science keyword support and ontology and service initiation and chaining. 


\section{Big Earth Data Initiative (BEDI)}

- Background:

- In 2013, the White House Office of Science and Technology Policy (OSTP) kicked off the Big Earth Data Initiative (BEDI) as a multiagency (NASA, NOAA, USGS) effort to make the collection of Earth Observation (EO) data more readily available and useful to users.

- The data directly supports 12 Societal Benefit Areas (SBAs).

- Funding provided to NASA FY14, FY15

- BEDI Objectives:

- Discovery - Make finding of datasets simpler

- Accessibility - Make datasets readily available to users

- Usability - Provide services to use datasets

- Task objectives for EOSDIS DAACs:

- Provide metadata to EOSDIS Common Metadata Repository (CMR)

- Maintain persistent identifiers for data collections via Digital Object Identifiers (DOIs)

- Make data available online via OPeNDAP or some other useful service

- Make imagery available in Worldview via GIBS

- Report metrics 


\section{Preservation}

NASA is not a "permanent archive" agency

- Must maintain "research archive" for as long as data are used for scientific research and/or transition responsibility to permanent archives

- Research archive responsibilities persist well beyond lives of missions

- NASA works with USGS and NARA for long-term preservation

- NASA has to ensure data and other critical items are preserved and made available to permanent archival agencies

- General requirements

- No loss of bits

- Discoverability and accessibility

- Readability

- Understandability

- Usability

- Reproducibility of results

- NASA has developed Preservation Content Specifications for Earth Science Data

- NASA is participating in Earth Science Information Partners (ESIP) Data Stewardship Committee, on an "emerging" Provenance and Context Content Standard 


\section{Categories of Content to be Preserved}

1. Preflight/Pre-Operations: Instrument/Sensor characteristics including preflight/pre-operations performance measurements; calibration method; radiometric and spectral response; noise characteristics; detector offsets

2. Science Data Products: Raw instrument data, Level 0 through Level 4 data products and associated metadata

3. Science Data Product Documentation: Structure and format with definitions of all parameters and metadata fields; algorithm theoretical basis; processing history and product version history; quality assessment information

4. Mission Data Calibration: Instrument/sensor calibration method (in operation) and data; calibration software used to generate lookup tables; instrument and platform events and maneuvers

5. Science Data Product Software: Product generation software and software documentation

6. Science Data Product Algorithm Input: Any ancillary data or other data sets used in generation or calibration of the data or derived product; ancillary data description and documentation

7. Science Data Product Validation: Records, publications and data sets

8. Science Data Software Tools: product access (reader) tools. 


\section{Conclusion}

- Success of EOSDIS has been based on its ability to meet and adapt to needs of diverse Earth science communities

- >20 years of diverse science data centers' operation to meet the needs of a growing user community

- >16 years of support for EOS missions (starting with TRMM)

- Working with new missions (e.g., EVS-1 aircraft investigations, EV-2 missions, SMAP, ICESat-2, OCO-2)

- Some key areas in which improvements are required and incremental progress is being made:

- Ease of discovery and access

- Cross-organizational interoperability

- Data inter-use

- Ease of collaboration

- Ease of citation of datasets

- Preservation of provenance and context and making them conveniently available to users 


\section{BACK-UP}




\section{EOSDIS ACSI Customer Satisfaction Survey 2014: Relative Rankings}

\section{EOSDIS ACSI Customer Satisfaction Survey 2014: \\ Relative Rankings}

- EOSDIS sponsors an annual independent customer survey in conjunction with the American Customer Satisfaction Index (ACSI)

- EOSDIS consistently exceeds the Federal Government average

- Ratings in the mid to upper 70s are considered "very good" by the rating organization, the CFI Group

- 2014 Survey results based on 4,147 responses

- Comments in surveys help define system improvements

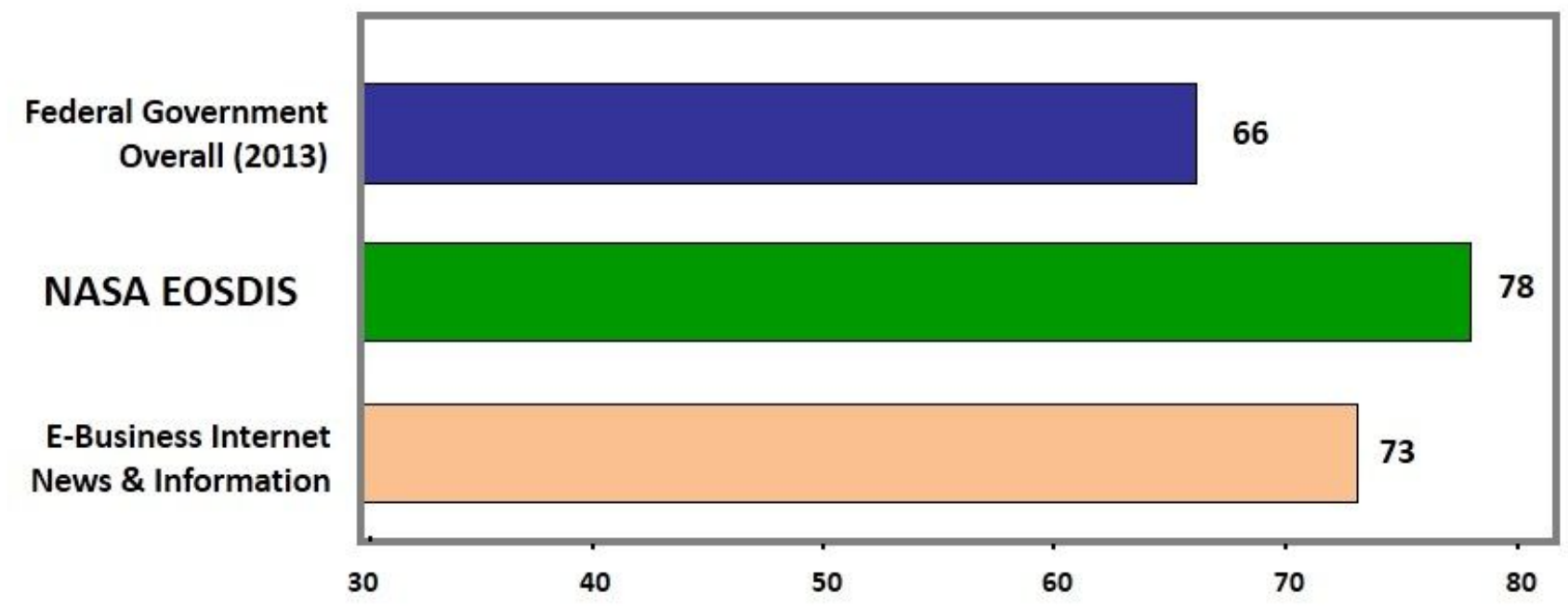




\section{EOSDIS Technology Improvements and System Evolution}

Lessons learned and information technology advances coupled with advice/comments from community supports a continuously evolving data system with growing capabilities

Disciplinel mission specific data systems

Communityspecific standards only

Data inter-use proved cumbersome
Support for high data volumes

Integrated core plus coupled elements

Cross-system search and order access via data interoperability mode

Common distribution format (HDF); other formats also supported tools and services

Options to support or interoperate with external data sources
Coexistence of heterogeneous, distributed data providers I information partners

- Minimal set of core standards; support for community-specific standards

- Preservation - content specifications

Reusable software

Service Oriented

Architecture

On-line archives and cross-system service invocation

Common data model

Expanded software
- Near Real-Time access

Ease of innovation and technology infusion

- Coherent Web earthdata.nasa.gov

- Common Metadata Repository

- User Registration System

- Full-Resolution, fast, image browse 


\section{EOSDIS Acronyms}

\begin{tabular}{|c|c|c|c|c|c|}
\hline ACSI & American Customer Satisfaction Index & GES & Goddard Earth Sciences & NRL & Naval Research Laboratory \\
\hline ACRIM & Active Cavity Radiometer Irradiance Monitor & GHRC & Global Hydrology Resource Center & NSIDC & National Snow and Ice Data Center \\
\hline AIRS & Atmospheric Infrared Sounder & GLAS & Geoscience Laser Altimeter System & OBPG & Ocean Biology Processing Group \\
\hline AMSR-E & Advanced Microwave Scanning for EOS & GMAO & Global Modeling and Assimilation Office & OGC & Open Geospatial Consortium \\
\hline API & Application programming interface & GMU & George Mason University & OMI & Ozone Monitoring Instrument \\
\hline ASTER & $\begin{array}{l}\text { Advanced Spaceborne Thermal Emission and Reflection } \\
\text { Radiometer }\end{array}$ & GRACE & Gravity Recovery and Climate Experiment & ORNL & Oak Ridge National Laboratory \\
\hline ASDC & Atmospheric Sciences Data Center & GSFC & Goddard Space Flight Center & PB & Peta Byte \\
\hline ASF & Alaska Satellite Facility & HDF & Hierarchical Data Format & PO.DAAC & Physical Oceanography DAAC \\
\hline AMSU & Advanced Microwave Sounding Unit & HIRDLS & High Resolution Dynamics Limb Sounder & RBD & Rate Buffered Data \\
\hline CALIPSO & $\begin{array}{l}\text { Cloud-Aerosol Lidar and Infrared Pathfinder Satellite } \\
\text { Observations }\end{array}$ & HSB & Humidity Sounder for Brazil & SAGE & Stratospheric Aerosol and Gas Experiment \\
\hline CDDIS & Crustal Dynamics Data Information System & IWGDD & Interagency Working Group on Digital Data & SAR & Side Aperture Radar \\
\hline CERES & Clouds and the Earth's Radiant Energy System & JPL & Jet Propulsion Laboratory & SEDAC & Socioeconomic Data and Applications Center \\
\hline CEOS & Committee on Earth Observation Satellites & LAADS & $\begin{array}{l}\text { Level } 1 \text { and Atmosphere Archive and Distribution } \\
\text { System }\end{array}$ & SIM & Spectral Irradiance Monitor \\
\hline CFI & Claes Fornell International & LANCE & Land, Atmosphere Near-real-time Capability for EOS & SIPS & Science Investigator-led Processing Systems \\
\hline DAAC & Distribute Active Archive Center & LIS & Lightning Imaging Sensor & SNOW-I & Search 'N Order Web Interface \\
\hline DISC & Data and Information Services Center & LP DAAC & Land Processes DAAC & SOLSTICE & Solar Stellar Comparison Experiment \\
\hline ECHO & EOS ClearingHOuse & ManLan & $\begin{array}{l}\text { Manhattan Landing (high performance exchange point } \\
\text { in New York City) }\end{array}$ & SORCE & Solar Radiation and Climate Experiment \\
\hline ECS & EOSDIS Core System & MISR & Multi-angle Imaging SpectroRadiometer & SPoRT & Short-term Prediction Research and Transition Center \\
\hline EDOS & EOS Data and Operations System & MLS & Microwave Limb Sounder & TB & Tera Byte \\
\hline EOC & EOS Operations Center & MODAPS & MODIS Data Processing System & TES & Tropospheric Emission Spectrometer \\
\hline EOS & Earth Observing System & MODIS & Moderate Resolution Imaging Spectroradiometer & TIM & TRMM Microwave Imager \\
\hline EOSDIS & EOS Data and Information System & MOPITT & Measurements of Pollution in the Troposphere & TRMM & Tropical Rainfall Measuring Mission \\
\hline ESDIS & Earth Science Data and Information System & MSFC & Marshall Space Flight Center & UMBC & University of Maryland, Baltimore County \\
\hline ESIP & Federation of Earth Science Information Partners & NASA & National Aeronautics and Space Administration & USGS & U.S. Geological Survey \\
\hline ESSI & Earth and Space Science Informatics & NGIX & Next Generation Internet Exchange & WGISS & Working Group on Information Systems and Services \\
\hline FGDC & Federal Geographic Data Committee & NISN & NASA Integrated Services Network & WIST & Warehouse Inventory Search Tool \\
\hline FRGP & Front Range GigaPOP & NITRD & $\begin{array}{l}\text { Networking and Information Technology Research and } \\
\text { Development }\end{array}$ & XPS & XUV Photometer System \\
\hline gbps & Giga bits per second & NPP & NPOESS Preparatory Project & & \\
\hline GCMD & Global Change Master Directory & NPOESS & $\begin{array}{l}\text { National Polar-orbiting Operational Environmental } \\
\text { Satellite System }\end{array}$ & & \\
\hline
\end{tabular}

